\title{
Differential Developmental Expression of the Rat Kininogen Genes ${ }^{1}$
}

\author{
SAMIR S. EL-DAHR, SUSANA DIPP, AND JULIE CHAO \\ Department of Pediatrics, Division of Pediatric Nephrology, Tulane University School of Medicine, \\ New Orleans, Louisiana, 70112 [S.S.E-D., S.D.]; and Department of Biochemistry and Molecular Biology, \\ Medical University of South Carolina, Charleston, South Carolina 29425 [J.C.]
}

\begin{abstract}
The rat liver expresses two low molecular weight kininogens ( $\mathrm{T}-\mathrm{KG}$ and $\mathrm{K}-\mathrm{KG}$ ). Although they share $90 \%$ of the nucleotide sequence in their $5^{\prime}$ flanking regions, $\mathrm{T}$ - and $\mathrm{K}-\mathrm{KG}$ genes are differentially regulated. The T-KG gene is inducible, and its protein is a potent thiol-protease inhibitor. In contrast, K-KG gene is expressed constitutively and encodes the precursor of the vasoactive nonapeptide bradykinin. To further elucidate the differential regulation of $\mathrm{T}$ - and $\mathrm{K}-\mathrm{KG}$ genes, we examined their developmental expression in the Sprague-Dawley rat. Northern blots of total liver RNA were probed with oligonucleotides complementary to $\mathrm{T}$ and $\mathrm{K}-\mathrm{KG}$ mRNA under highstringency conditions. A single T-KG mRNA $(1.8 \mathrm{~kb})$ and two K-KG mRNA species (1.6 and $2.3 \mathrm{~kb})$ were consistently detected at all ages studied. Steady state T-KG mRNA levels increased 3.5-fold at birth and remained high during the 1st week of postnatal life only to decline thereafter. T-KG immunoreactivity in the liver and plasma determined by Western blot analysis paralleled T-KG mRNA expression. In marked contrast, K-KG mRNA expression was not altered during the transition from fetal to neonatal life, nor was it affected by postnatal maturation. The results demonstrate that the fetal rat liver synthesizes kininogens and that T- and K-KG genes are differentially regulated during development. Up-regulation of T-KG synthesis after birth may serve a protective function in the newborn via its antiprotease activity. Our previous finding that the tissue kallikrein gene is up-regulated with age is in marked contrast with the constitutive expression of its substrate, suggesting that kallikrein synthesis is the ratelimiting factor for bradykinin formation during postnatal maturation. (Pediatr Res 32: 649-653, 1992)
\end{abstract}

\section{Abbreviations}

LMW, Low molecular weight

HMW, High molecular weight

$\mathrm{KG}$, kininogen

TdT, terminal deoxynucleotide transferase

GRE, glucocorticoid response element

The liver is the main organ that synthesizes and releases $\mathrm{KG}$. There are two forms of $\mathrm{KG}$, the HMW and the LMW KG.

Received May 14, 1992; accepted July 29, 1992.

Correspondence: Samir S. El-Dahr, M.D., Department of Pediatrics, Tulane University School of Medicine, 1430 Tulane Ave., New Orleans, LA 70112.

Supported in part by a grant-in-aid from the American Heart Association, Louisiana Affiliate.

'Portions of this study were presented at the Society for Pediatric Research meeting, New Orleans, LA, May 1991, and were published in abstract form (Pediatr Res 29:341, 1991).
HMW and LMW KG mRNA are identical in nucleotide sequence in the $5^{\prime}$ terminal portion but diverge completely in the $3^{\prime}$-terminal portion. The two mRNA species are generated from a single gene by differential splicing of the primary transcript (1). In humans, LMW KG is cleaved by tissue kallikrein releasing the vasoactive peptide Lys-bradykinin $(2,3)$. In the rat, two LMW KG have been characterized (T and K) (4-6). T-KG gene expression is induced dramatically by inflammation and therefore is considered an acute-phase protein (7). T-KG is kallikreinresistant but is cleaved by T-kininogenase (8) generating T-kinin (isoleucyl-seryl-bradykinin), which shares many pharmacologic properties with bradykinin (9). In contrast, the $\mathrm{K}-\mathrm{KG}$ gene is not induced by inflammation (10) and is considered the equivalent of human LMW KG (5). Rat HMW and LMW K-KG are cleaved by rat tissue kallikrein to release bradykinin (11).

In addition to biochemical and regulatory differences, $\mathrm{T}$ - and $\mathrm{K}-\mathrm{KG}$ possess different biologic functions. T-KG is a powerful cysteine proteinase inhibitor (12), and its synthesis and release in response to tissue damage and inflammation may serve an important protective function. $\mathrm{K}-\mathrm{KG}$, on the other hand, primarily serves as the precursor of vasoactive peptide bradykinin, which plays an important role in mediating pain, capillary permeability, organ blood flow, renal hemodynamics, and solute and water excretion $(2,3)$.

In the present study, we provide further evidence for the differential regulation of $\mathrm{T}-$ and $\mathrm{K}-\mathrm{KG}$ genes in the rat and speculate on the responsible molecular mechanisms. Specifically, we have investigated the effects of development on these genes for the following reasons: 1 ) many tissue-specific genes are developmentally regulated-we wished to determine whether the closely related $\mathrm{T}$ - and $\mathrm{K}-\mathrm{KG}$ genes are differentially regulated during development; and 2) we have recently reported that the fetal and newborn rat kidneys express the tissue kallikrein gene and its protein (13), and in this study, we wished to determine whether the developing animal synthesizes the kallikrein substrate, K-KG. Given the homology in nucleotide sequence between the rat T- and $\mathrm{K}-\mathrm{KG}\left(90 \%\right.$ in exon- 1 and the $5^{\prime}$ upstream region), we used gene-specific oligonucleotides to probe for $\mathrm{T}$ and $K-K G$ transcripts. In addition, specific polyclonal $T-K G$ antibodies were used to detect the translational products of the $\mathrm{T}-\mathrm{KG}$ gene.

\section{MATERIALS AND METHODS}

Time-dated pregnant and adult Sprague-Dawley rats were purchased from Charles River Breeding Laboratories, (Wilmington, MA) and fed regular rat Chow (Purina 5012; Ralston-Purina, St. Louis, MO) and tap water until the day of experiments. Fetuses (at 15, 17, 18, 19, and $20 \mathrm{~d}$ of gestation) and newborn (at $1,5,12$, and $20 \mathrm{~d}$ of postnatal life) and male adult (150-250 g) rats were studied.

On the day of study, adult rats were killed by decapitation into liquid nitrogen. For the ontogeny studies, pregnant rats were 
anesthetized with intraperitoneal pentobarbital $(5 \mathrm{mg} / 100 \mathrm{~g}$ body weight); the fetuses were delivered through a midabdominal incision and immediately decapitated into liquid nitrogen. The mothers were subsequently killed by intracardiac injection of a saturated solution of potassium chloride.

Western blot analysis. Livers were pooled from five to six rats in each age group, whereas the plasma was collected from newborn and adult rats only. The livers were removed, rinsed thoroughly, and homogenized in PBS ( $\mathrm{pH} 7.2$ ) on ice. Homogenates were centrifuged at $600 \times g$ for $20 \mathrm{~min}\left(4^{\circ} \mathrm{C}\right)$, and the supernatant was treated with deoxycholate $(0.5 \% \mathrm{wt} / \mathrm{vol})$ for $30 \mathrm{~min}$ at room temperature and centrifuged at $20000 \times g$ for $30 \mathrm{~min}$ at $4^{\circ} \mathrm{C}$. The samples were subsequently assayed for protein concentrations according to the method of Lowry et al. (14) using BSA as a standard.

Aliquots of liver extract (50-100 $\mu \mathrm{g}$, total protein) were separated by $3-12 \%$ stacking SDS-PAGE $[12 \%$ acrylamide, $5 \mathrm{mM}$ Bis (Bio-Rad Laboratories, Richmond, CA), $0.38 \mathrm{M}$ Tris- $\mathrm{HCl}$, pH $8.8,0.1 \%$ SDS, $0.1 \%$ ammonium persulfate, and $0.025 \%$ TEMED (Bio-Rad)]. Rainbow molecular weight markers (14 300-200 000; Amersham, Arlington Heights, IL) were used to determine approximate molecular weight. Electrophoresis was carried out at $60 \mathrm{~V}$ for $3 \mathrm{~h}$, in duplicate. One gel was stained with $0.1 \%$ Coomassie blue stain R250 to visualize the protein bands. The proteins from the second gel were electrophoretically transferred to nitrocellulose in a Genie Electrophoretic Blotter (Idea Scientific, Corvallis, OR) at $20 \mathrm{~V}$ for $90 \mathrm{~min}$. Transfer buffer is Tris-glycine ( $25 \mathrm{mM}$ Tris, $0.2 \mathrm{M}$ glycine), $\mathrm{pH} 8.3$, in $20 \%$ methanol. After transblotting, the nitrocellulose was washed in PBS, pH 7.2, and incubated overnight at $4^{\circ} \mathrm{C}$ in PBS containing 3\% BSA as a blocking agent. After rinsing in $0.05 \%$ Tween 20 in PBS for $20 \mathrm{~min}$ at room temperature, the nitrocellulose was incubated with rabbit antirat T-KG antiserum (15) (diluted 1:1000 in PBS-Tween 20) for $2 \mathrm{~h}$ at room temperature. The nitrocellulose was then washed in PBS-Tween 20 followed by PBS alone and incubated at room temperature for $1 \mathrm{~h}$ with antirabbit IgG peroxidase conjugate raised in goat (Sigma Chemical Co., St. Louis, MO; diluted 1:2000 in PBS-Tween 20 with $3 \%$ BSA). After washing the blots in PBS, visualization of antigen-antibody reaction products was accomplished by adding 60 $\mathrm{mg}$ of 4-chloro-1-naphthol dissolved in $20 \mathrm{~mL}$ methanol to $0.05 \% \mathrm{H}_{2} \mathrm{O}_{2}$ in PBS.

Northern blot analysis using $T$ - and $K-K G$ oligonucleotide probes. Total liver RNA was extracted using the guanidinium isothiocyanate-phenol-chloroform method of Chomczynski and Sacchi (16) from fetuses at 2 and $1 \mathrm{~d}$ before birth ( $n=10 /$ group); newborns at postnatal d $1(n=8), \mathrm{d} 5(n=8), \mathrm{d} 12(n=7)$, and d $20(n=7)$, and adults $(n=6)$. RNA was quantified spectrophotometrically by absorbance at 260 and $280 \mathrm{~nm}$. Only samples with $\mathrm{A}_{260 / 280}$ ratio over 1.8 were used. The extracted RNA was pooled for each age group of animals for the Northern blot analysis, whereas RNA extracted from individual animals was used for further quantitative measurements by slot blot analysis ( $n=4-6 /$ group). RNA was dissolved in sterile water and stored at $-70^{\circ} \mathrm{C}$ until use. Precipitated denatured RNA $(15-20 \mu \mathrm{g})$ was subjected to $1.2 \%$ agarose $/ 2.2 \mathrm{M}$ formaldehyde gel electrophoresis. RNA was then transferred into a positively charged nylon membrane (Zetabind; AMF Cuno, Inc., Meriden, CT) and crosslinked by exposure to UV light for $1 \mathrm{~min}$. Equal transfer of RNA to the membrane was confirmed by UV shadowing at $254 \mathrm{~nm}$. Slot blots were prepared by dissolving 2-0.5 $\mu \mathrm{g}$ of total RNA in $0.5 \mathrm{~mL}$ of sterile $25-\mathrm{mM}$ sodium phosphate buffer ( $\mathrm{pH} 7.2$ ) and applying this RNA to a Zetabind membrane preequilibrated with the same buffer by use of a Minifold II Slot-Blotter (Schleicher \& Schuell, Keene, NH). The blot was allowed to dry at room temperature, and equal RNA loading was confirmed by UV shadowing at $254 \mathrm{~nm}$.

The DNA probes consisted of synthetic HPLC-purified oligomers complementary to T-KG and K-KG mRNA (6). The TKG oligonucleotide sequence is 5'-GACACAGAGGTCCT-
CCTCTGTCTTCTTA-3'; the K-KG oligomer sequence is $5^{\prime}$ CAGACAGTGGTACTCGTTTGTCACTATG- $3^{\prime}$. The oligonucleotides were $3^{\prime}$-end-labeled with $\alpha{ }^{32}$ P-deoxy ATP using the enzyme TdT as described by Henderson et al. (17) with few modifications. The reaction mixture contained $30 \mathrm{ng}(1.5 \mu \mathrm{L})$ of oligonucleotide, $2.5 \mu \mathrm{L}$ RNase-free water, $4 \mu \mathrm{L}$ of $5 \times$ TdT buffer (BRL Gibco, Grand Island, NY), $10 \mu \mathrm{L}$ (33 pmol) of $\alpha{ }^{32} \mathrm{P}$-deoxy ATP $(6000 \mathrm{Ci} / \mathrm{mmol}$, DuPont-New England Nuclear, Boston, MA), and 30 units $(2 \mu \mathrm{L})$ of TdT (BRL, Gibco). After incubation at $37^{\circ} \mathrm{C}$ for $1 \mathrm{~h}$, the reaction was stopped by adding $10 \mu \mathrm{L}$ of icecold RNase-free water. Unincorporated nucleotides were removed from the reaction mixture using NENSORB-20 cartridges by following the manufacturer's recommendations (DuPontNew England Nuclear). Sp act was $1-3.3 \times 10^{9} \mathrm{cpm} / \mu \mathrm{g}$ of DNA.

Northern blots were prehybridized at $54^{\circ} \mathrm{C}$ for $4 \mathrm{~h}$ in $1 \times$ SSPE $(0.15 \mathrm{M} \mathrm{NaCl}, 0.01 \mathrm{M}$ sodium phosphate, $0.001 \mathrm{M}$ EDTA, $\mathrm{pH}$ $7.4), 2 \times$ Denhardt's solution, $10 \%$ dextran sulfate, $2 \%$ SDS, and $200 \mu \mathrm{g} / \mathrm{mL}$ herring sperm DNA. The labeled probe was added at a final concentration of $2 \times 10^{6} \mathrm{cpm} / \mathrm{mL}$, and hybridization was carried out at $54^{\circ} \mathrm{C}$ for $40 \mathrm{~h}$. Posthybridization washes consisted of $1 \times \mathrm{SSPE} / 0.5 \% \mathrm{SDS}$ and $0.2 \times \mathrm{SSPE} / 1 \% \mathrm{SDS}$ at room temperature ( $30 \mathrm{~min}$ each) and $0.1 \times \mathrm{SSPE} / 0.5 \% \mathrm{SDS}(30$ min at $54^{\circ} \mathrm{C}$ ). Signals were detected by autoradiography (Kodak XOMAT-AR and -RP films Eastman Kodak Co., Rochester, $\mathrm{NY}$ ) in the presence of one or two image-intensifying screens and quantified by scanning densitometry. The Northern blots were stripped off the oligonucleotide probe $(0.1 \times \mathrm{SSPE} / 0.5 \%$ SDS for $60 \mathrm{~min}$ at $95^{\circ} \mathrm{C}$ ) and reprobed for the constitutively expressed nonmuscle $\beta$-actin gene using a $\beta$-actin cDNA (18) labeled with $\alpha{ }^{32} \mathrm{P}$-deoxycytidine triphosphate by random primer technique (19).

Comparisons of the densitometric values in the slot blots among the age groups were performed by one-way analysis of variance and Newman-Kuels test. Statistical significance is defined as $p<0.05$, and the results are presented as means \pm SEM.

\section{RESULTS}

Fetal rat liver expresses $T$ - and $K-K G$ genes. It is well established that the adult rat liver expresses the T-and K-KG genes (10). Recently, Mann and Lingrel (20) demonstrated that the fetal liver expresses T-KG mRNA. In this report, we confirm their results (Fig. 1) and show that the T-KG oligonucleotide hybridized to a single $1.8-\mathrm{kb}$ mRNA species and that the relative amounts of T-KG mRNA in the near-term fetal liver are at least as large as those in the adult liver.

We also show that the fetal liver expresses K-KG mRNA transcripts (Fig. 1). The K-KG oligonucleotide hybridized consistently to two mRNA species $(1.6$ and $2.3 \mathrm{~kb})$. We have also observed on occasion a band of about $4.0 \mathrm{~kb}$. The $1.6-\mathrm{kb}$ mRNA is considered to be the equivalent to the human $\mathrm{LMW} \mathrm{KG}$, whereas the higher mRNA species represent the HMW KG $(6,10)$.

Effect of birth on $T$ - and $K-K G$ expression. Birth had a stimulatory effect on the $\mathrm{T}-\mathrm{KG}$ gene. $\mathrm{T}-\mathrm{KG}$ steady state mRNA accumulation increased by more than 3.5 -fold from late prenatal to postnatal life (Figs. 1 and 2). In contrast, hepatic K-KG gene expression did not appear to change during the transition from fetal to neonatal life (Fig. 1). Densitometric analysis of RNA slot blots of individual livers indicated that the 1- and 5-d-old newborn rats expressed significantly more T-KG mRNA than the late gestation fetuses $(p<0.001)$, whereas $\mathrm{K}-\mathrm{KG}$ mRNA levels remained relatively stable during that period (Fig. 2).

Postnatal expression of $K G$ genes. After delivery, T-KG mRNA levels peaked on $d 1$ of postnatal life and remained expressed at high levels during the first $5 \mathrm{~d}$ after birth (Figs. 1 and 2). The adult liver had the lowest steady state levels of $T$ KG mRNA across all age groups. In contrast, expression of the 1.6- or 2.3-kb K-KG mRNA did not change appreciably from the early postnatal period to adulthood (Figs. 1 and 2). 

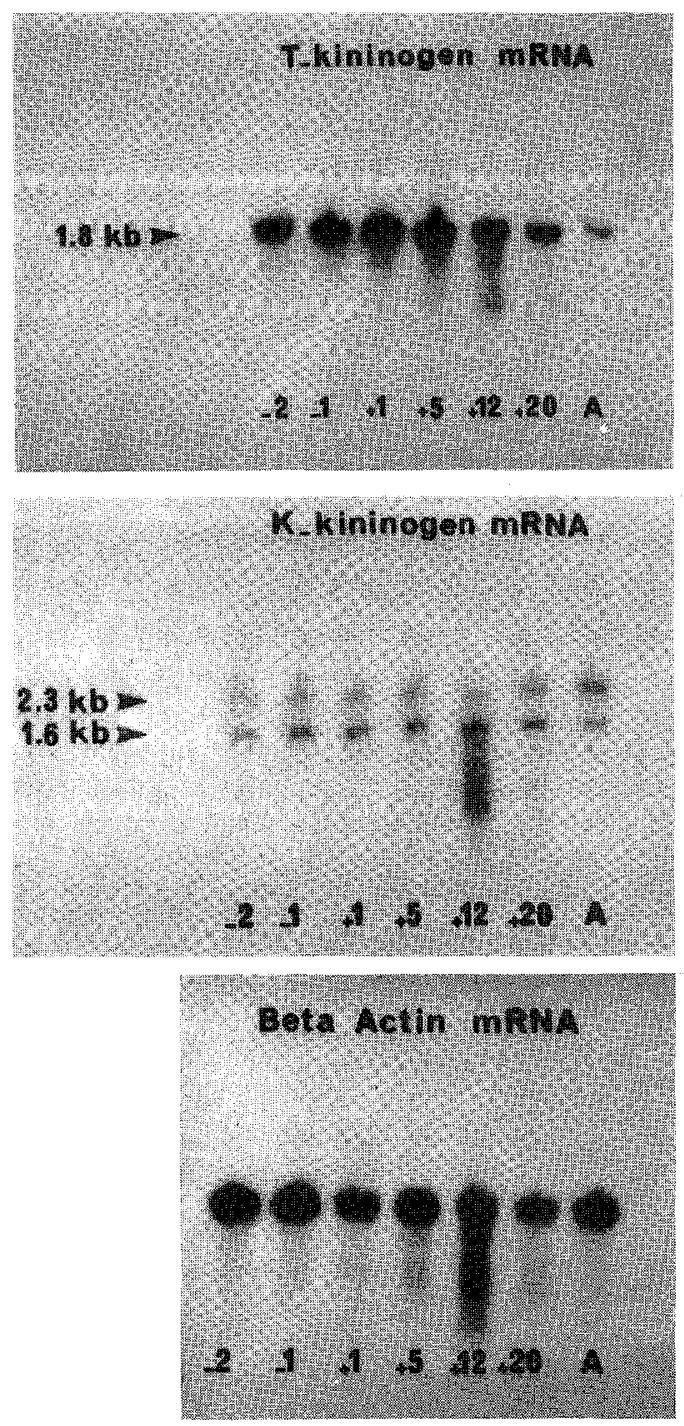

Fig. 1. Ontogeny of $\mathrm{T}$ - and $\mathrm{K}-\mathrm{KG}$ gene expression. Northern blots of total liver RNA (15-20 $\mu \mathrm{g} /$ lane) were probed with ${ }^{32} \mathrm{P}$-labeled $\mathrm{T}$ - and $\mathrm{K}-\mathrm{KG}$ oligonucleotides or $\beta$-actin cDNA. Negative numbers $=$ days before birth; positive numbers $=$ days after birth; $A$, adult. The nearterm fetus expresses both T- and K-KG mRNA. The transition from fetal to newborn life up-regulates T-KG mRNA expression (top). In contrast, $\mathrm{K}-\mathrm{KG}$ mRNA species $(1.6$ and $2.3 \mathrm{~kb}$ ) did not change with maturation (middle). Bottom panel shows liver $\beta$-actin mRNA expression.

Hepatic and circulating $T-K G$ protein expression during maturation. Western blot analysis of liver proteins using the polyclonal T-KG antibody revealed a $68-\mathrm{kd}$ immunoreactive band that was first detectable at d 17 of fetal life ( $4 \mathrm{~d}$ before birth) (Fig. 3, upper panel). HMW KG was not detected, confirming the specificity of the antibody for LMW KG. T-KG immunoreactivity increased toward the end of gestation. Similar to the expression of its mRNA, T-KG protein levels peaked on the day after birth, remained relatively high during the first $5 \mathrm{~d}$ of postnatal life, and were followed by an age-related decline in $\mathrm{T}$ KG immunoreactivity.

The temporal expression of T-KG was qualitatively similar in the liver and plasma. Plasma proteins obtained from newborn and adult rats expressed a 68-kd immunoreactive band when probed with the T-KG antibody (Fig. 3, lower panel). The intensity of the 68-kd band was higher in newborn than adult rats, indicating that synthesis and release of hepatic T-KG are coupled throughout postnatal maturation.

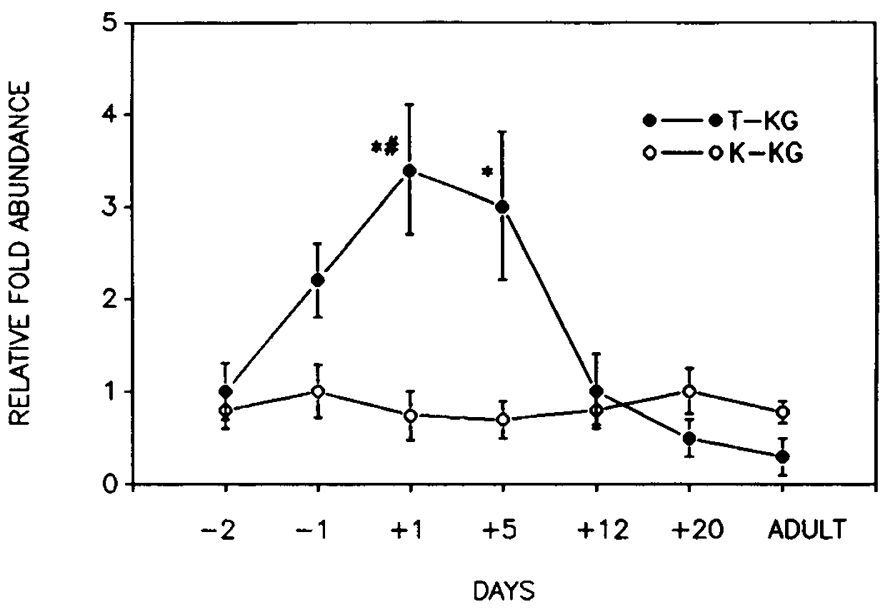

Fig. 2. Densitometric results of RNA slot blot analysis of $T$ - and K-KG mRNA during liver maturation (means \pm SEM; $n=4-6 /$ age group). Negative numbers $=$ days before birth; positive numbers $=$ days after birth. A value of 1 was arbitrarily assigned to the level of mRNA present at $2 \mathrm{~d}$ before birth. ${ }^{*} p<0.001$ vs $\mathrm{d}-2,+12,+20$, and adult; $\# p$ $<0.05$ vs $\mathrm{d}-1$.
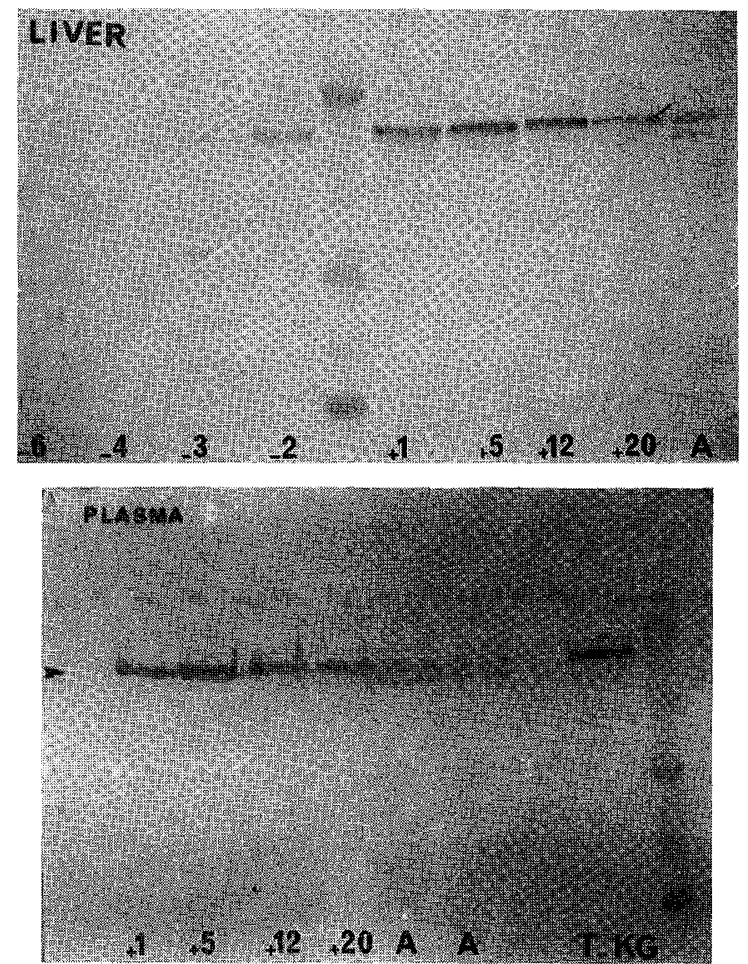

Fig. 3. Maturational changes in T-KG protein expression. Western blot of liver protein extracts ( $100 \mu \mathrm{g}$ total protein/lane) was probed with polyclonal T-KG antibody $(t o p)$. Western blot of plasma proteins $(50 \mu \mathrm{g}$ total protein/lane) was probed with the polyclonal T-KG antibody (bottom). Negative numbers $=$ days before birth; positive numbers $=$ days after birth.

\section{DISCUSSION}

Compared with other species, including humans, the rat is unique in that this species expresses more than one LMW KG gene $(5,6)$. The rat is the only species known to express the $\mathrm{T}-\mathrm{KG}$ gene. This gene is expressed in a tissue-specific manner and is induced by inflammation $(7,10)$. More recently, the hepatic $\mathrm{T}-\mathrm{KG}$ gene was also found to be developmentally regulated; its expression is highest during the immediate postnatal period and decreases significantly thereafter (20). The rat K-KG gene, on the other hand, is the counterpart of human and bovine 
LMW KG, the substrate for tissue kallikreins, and the precursor of the vasoactive peptide bradykinin (5). This gene does not encode an acute-phase protein and is not up-regulated in response to tissue injury (10).

The most important finding of the present study is that despite substantial nucleotide sequence homology between the two KG genes, only the $\mathrm{T}-\mathrm{KG}$ gene is subject to developmental regulation, whereas the gene encoding $\mathrm{K}-\mathrm{KG}$ does not appear to be under significant developmental control. Importantly, much of the developmental changes in T-KG occurred around the time of birth, suggesting that perinatal events may be involved in this effect. Stress appears to be a common inducer of T-KG gene expression; tissue injury and inflammation are powerful inducers of T-KG $(7,15)$. Preliminary results from our laboratory also showed a significant up-regulation of hepatic $\mathrm{T}-\mathrm{KG}$ but not $\mathrm{K}-\mathrm{KG}$ gene expression in response to chronic unilateral ureteral obstruction in the rat (manuscript in preparation). Whether the stress of delivery (hypoxia and acidosis) plays a role in mediating the perinatal changes in T-KG gene expression remains to be determined. The presence of multiple GRE in the T-KG upstream region also suggests that the perinatal surge in glucocorticoid secretion may be involved in stimulating $\mathrm{T}-\mathrm{KG}$ expression at the transcriptional level (20).

Control of gene transcription is mediated by protein-protein and protein-DNA interactions that, for the most part, take place in the $5^{\prime}$ upstream region of the target gene (21-23). Comparison of $\mathrm{T}$ - and K-KG genes reveals that the two genes have $90 \%$ sequence homology in their 1st exons and in the $5^{\prime}$ flanking regions; the homology decreases to about $50-60 \%$ toward the $3^{\prime}$ regions (6). A TATA box-like sequence (a consensus sequence present about 25-35 bp from the start site of most genes that accounts for a major part of basal promoter activity) is not found in the $5^{\prime}$ flanking regions of either $\mathrm{T}$ - or $\mathrm{K}-\mathrm{KG}$ genes. Other common promoter consensus sequences (CCAAT and GC boxes) are also absent. Rather, the two genes contain AT-rich sequences (AT content is higher in T-KG) about $28 \mathrm{bp}$ from the transcription initiation site. Eight GRE are present in their upstream regions. Reporter gene transfection studies revealed that one of these GRE located at -119 to -124 (from transcription start site) is able to confer full inductivity to exogenous glucocorticoids (24).

It is possible that, given the appropriate developmental stimulus (e.g. labor or birth), de novo expression or activation of sequence-specific DNA-binding protein(s) occurs. To promote differential cell-specific (hepatocyte) expression of T- and K-KG genes, however, one must assume that the induced transcription factor(s) is extremely specific for its cognate cis-acting elements in that it recognizes even a single base difference between the upstream regulatory regions of the two genes. An example of this would be in the consensus sequence for the glucocorticoid receptor present at nucleotides -65 to -69 . This sequence matches the putative GRE $\left(5^{\prime}-\right.$ TGTTCT) in the T-KG gene. In the $K-K G$ gene, the $C$ in the latter sequence is replaced by $T$. Alternatively, because the $\mathrm{T}$ and $\mathrm{K}$ genes diverge in sequence in the $3^{\prime}$ portions of their sequence, it is conceivable that the transcriptional regulation is mainly exerted in that portion of the gene rather than at the $5^{\prime}$ end. The developmental expression of $\mathrm{KG}$ genes may also be regulated at the transcriptional level via a temporally programmed demethylation of $\mathrm{CpG}$ bases (25). Several liver-specific genes are subject to demethylation after their activation in the fetal liver, including the rat phosphoenolpyruvate carboxykinase and albumin genes $(26,27)$. It is believed that these genes are first activated by DNA methylation-independent mechanisms; this is followed by gene demethylation, which now allows the transcription to proceed independent of the initial differentiation factors. Further studies are needed to explore all these possibilities.

The Western blotting results demonstrate that the fetal liver is capable of translating the KG message into its proper molecular mass protein and secreting it into the circulation. The physiologic significance of the postnatal surge in hepatic $\mathrm{T}-\mathrm{KG}$ synthesis is not known. However, given that $\mathrm{T}-\mathrm{KG}$ is an inhibitor of lysosomal cysteine proteinases (cathepsins) (12), it seems likely that the high tissue and circulating levels of antiprotease activity serve a protective role in the newborn animal. In this regard, it has been proposed that a low $\mathrm{pH}$ environment generated in a restricted space outside the cell may activate these proteinases, which in turn can activate latent collagenases, thereby playing an indirect role in degrading the extracellular matrix (28).

The present study is the first to describe the developmental expression of the K-KG gene that encodes for the kallikrein substrate. We detected K-KG mRNA sequences in the near-term fetal and neonatal liver. Unlike T-KG, however, K-KG mRNA levels did not change appreciably with maturation. Unfortunately, the lack of antibodies against rat $\mathrm{K}-\mathrm{KG}$ prevented us from evaluating the expression of the $K-K G$ protein. We have recently demonstrated that the fetal and newborn kidneys express the true tissue kallikrein gene and that renal kallikrein synthesis increases 6-fold during the transition from newborn to adult life (13). Similar findings were reported for kallikrein mRNA in the submandibular gland (29). Thus, considering the constant levels of K-KG expression during maturation, it appears that the rate of kallikrein synthesis is probably most important in determining the final activity of the kallikrein-kinin system during normal growth.

In conclusion, the present study shows that the fetal rat liver expresses the kininogen genes. However, only the $\mathrm{T}-\mathrm{KG}$ is subject to developmental control and is up-regulated in the immediate postnatal period. In contrast, the $\mathrm{K}-\mathrm{KG}$ gene is expressed in a constitutive manner and is not induced by maturation. Studies of the developmental expression of kininogen genes will not only enhance our understanding of the role of kinins during early life, but will likely provide a suitable model for the study of differential gene regulation in eukaryotes.

\section{REFERENCES}

1. Kitamura N, Takagashi Y, Furuto S, Tanaka T, Nakanishi S 1983 A single gene for bovine high molecular weight and low molecular weight kininogen. Nature 305:545-549

2. Margolius HS 1989 Tissue kallikrein and kinins: regulation and roles in hypertensive and diabetic diseases. Annu Rev Pharmacol Toxicol 29:343364

3. Carretero OA, Scicli AG 1989 Kinins, paracrine hormones, in the regulation of blood flow, renal function, and blood pressure. In: Laragh $\mathrm{JH}$, Brenner BM, Kaplan NM (eds) Endocrine Mechanisms in Hypertension. Raven Press, New York, pp 219-239

4. Okamoto H, Greenbaum LM 1983 Isolation and structure of T-kinin. Biochem Biophys Res Commun 112:701-708

5. Furuto-Kato S, Matsumoto A, Kitamura N, Nakanishi S 1985 Primary structures of the mRNAs encoding the rat precursors for bradykinin and T-kinin. J Biol Chem 260:12054-12059

6. Fung W-P, Schreiber G 1987 Structure and expression of the genes for major acute phase $\alpha_{1}$-protein (thiostatin) and kininogen in the rat. $\mathbf{J}$ Biol Chem 262:9298-9308

7. Chao J, Swain C, Chao S, Xiong W, Chao L 1988 Tissue distribution and kininogen gene expression after acute-phase inflammation. Biochim Biophys Acta 964:329-339

8. Barlas A, Gao X, Greenbaum LM 1987 Isolation of a thiol-activated Tkininogenase from the rat submandibular gland. FEBS Lett 218:266-270.

9. Okamoto H, Greenbaum LM 1983 Pharmacological properties of $\Upsilon$-kinin (isoleucyl-seryl-bradykinin) from rat plasma. Biochem Pharmacol 32:26372638

10. Kageyama R, Kitamura N, Ohkubo H, Nakanishi S 1985 Differential expression of the multiple forms of rat prekininogen mRNAs after acute inflammation. J Biol Chem 260:12060-12064

11. Kato H, Enjyoji K, Miyata T, Hayashi T, Oh-ishi S, Iwanaga S 1985 Demonstration of arginyl-bradykinin moiety in rat HMW kininogen: direct evidence for liberation of bradykinin by rat glandular kallikreins. Biochem Biophys Res Commun 127:289-295

12. Sueyoshi T, Enjyoji T, Shimada T, Kato H, Iwanaga S, Bando Y, Kominami E, Katunuma N 1985 A new function of kininogens as thio-proteinase inhibitors: inhibition of papain and cathepsins $B, H$, and $L$ by bovine, rat and human plasma kininogens. FEBS Lett 182:193-195

13. El-Dahr SS, Chao J 1992 Spatial and temporal expression of kallikrein and its mRNA during nephron maturation. Am J Physiol 262:F705-F711

14. Lowry OH, Rosebrough NJ, Farr AL, Randal RJ 1951 Protein measurement with the Folin phenol reagent. J Biol Chem 193:265-275 
15. Xu J, Hsu CY, Junker H, Chao S, Hogan EL, Chao J 1991 Kininogen and kinin in experimental spinal cord injury. J Neurochem 57:975-980

16. Chomczynski P, Sacchi N 1987 Single-step method of RNA isolation by acid guanidinium thiocyanate-phenol-chloroform extraction. Anal Biochem 162:156-159

17. Henderson GS, Conary JT, Davidson JM, Stewart SJ, House FS, McCurley TL 1991 A reliable method for northern blot analysis using synthetic oligonucleotide probes. Biotechniques 10:190-197

18. Corjay MH, Thompson MM, Lynch KR, Owens GK 1989 Differential effect of platelet-derived growth factor versus serum-induced growth on smooth muscle $\alpha$-actin and nonmuscle $\beta$-actin RNA expression in cultured rat aortic smooth muscle cells. J Biol Chem 264:10501-10506

19. Feinberg AP, Vogelstein B 1984 A technique for radiolabeling DNA restriction endonuclease fragments to high specific activity. Anal Biochem 137:266267

20. Mann EA, Lingrel JB 1991 Developmental and tissue-specific expression of rat T-kininogen. Biochem Biophys Res Commun 174:417-423
21. Maniatis T, Goodbourn S, Fischer JA 1987 Regulation of inducible and tissuespecific gene expression. Science 236:1237-1245

22. Johnson PF, McKnight SL 1989 Eukaryotic transcriptional regulatory proteins Annu Rev Biochem 58:799-839

23. Mitchell PJ, Tjian R 1989 Transcriptional regulation in mammalian cells by sequence-specific DNA binding proteins. Science 245:371-378

24. Anderson KP, Lingrel JB 1989 Glucocorticoid and estrogen regulation of a rat T-kininogen gene. Nucleic Acids Res 17:2835-2848

25. Cedar H, Razin A 1990 DNA methylation and development. Biochim Biophys Acta 1049:1-8

26. Benvenisty N, Mencher D, Meyuhas O, Razin A, Reshef L 1985 Sequential changes in DNA methylation patterns of the rat phosphoenolpyruvate gene during development. Proc Natl Acad Sci USA 82:267-271

27. Kunnath L, Locker J 1983 Developmental changes in the methylation of the rat albumin and $\alpha$-fetoprotein genes. EMBO J 2:317-324

28. Davies M, Martin J, Thomas GJ, Lovett DH 1992 Proteinases and glomerular matrix turnover. Kidney Int 41:671-678

29. Clements JA, Matheson BA, Funder JW 1990 Tissue-specific developmental expression of the kallikrein gene family. J Biol Chem 265:1077-1081 